\title{
Optical Properties of Nano-Crystalline Zirconia Thin Films Prepared at Different Post-Oxidation Annealing Times
}

\author{
A. Hojabri* And S. Pourmohammad \\ Department of Physics, Karaj Branch, Islamic Azad University, Karaj, Iran
}

\begin{abstract}
The zirconia $\left(\mathrm{ZrO}_{2}\right)$ is one of the transition-metal oxides with most excellent optical properties which thus attracts great attention in optical engineering. A variety of methods were used for deposition of $\mathrm{ZrO}_{2}$ thin films on different substrates. In the present work, homogenous, transparent nanocrystalline zirconia thin films were grown by thermal oxidation of zirconium ( $\mathrm{Zr}$ ) thin films deposited on quartz substrate using DC magnetron sputtering technique. The objective of this study is to reveal the effect of thermal oxidation time on structural and optical properties of deposited films. The XRD results revealed the formation of single phase $\mathrm{ZrO}_{2}$ with tetragonal structure in the films at different thermal oxidation times. The optical constant of $\mathrm{ZrO}_{2}$ thin films was calculated from the UV-visible transmission spectra. It was found that the increase of thermal oxidation time leads to the increase of transmittance and optical band gap energy of the films. The AFM results showed that thermal oxidation time influences the surface morphology of the films.
\end{abstract}

DOI: 10.12693/APhysPolA.129.647

PACS/topics: 81.40.Tv, 81.07.Bc, 81.15.cd

\section{Introduction}

In recent years, zirconium dioxide (zirconia, $\mathrm{ZrO}_{2}$ ) thin films, owing to excellent optical, thermal, mechanical and electrical properties [1-10], have been widely used in diverse fields, such as optical filters, anti-corrosion, protective and thermal barriers, gas sensor, anti-reflection coating $[8,9]$ and as insulators in microelectronic devices [10]. Depending on deposition technique, its parameters and heat treatment, $\mathrm{ZrO}_{2}$ films can exist in various phases, monoclinic, tetragonal, cubic and amorphous $[3,8,9]$. A variety of chemical and physical methods were employed for preparation of $\mathrm{ZrO}_{2}$ thin films on different substrates such as metal organic chemical vapor deposition (MOCVD) [8], reactive sputtering [5], electron beam evaporation [3]. In the present work, a simple, low-cost and flexible method of post-oxidation annealing of the $\mathrm{Zr}$ thin films was employed for preparation of $\mathrm{ZrO}_{2}$ thin films. The structural and optical changes in $\mathrm{ZrO}_{2}$ thin films were investigated by annealing time variation during thermal oxidation annealing process of the as-deposited zirconium films.

\section{Experimental details}

In the first step, zirconium $(\mathrm{Zr})$ thin films were deposited on quartz substrates by dc magnetron sputtering technique at room temperature. The zirconium target was of purity of $99.999 \%$. The substrates were cleaned ultrasonically with acetone and ethanol for $10 \mathrm{~min}$ and then dried in $\mathrm{N}_{2}$ gas before introducing into the deposition chamber. The target to substrate distance was kept

*corresponding author; e-mail: hojabri@kiau.ac.ir at $4.5 \mathrm{~cm}$. The base pressure was $5.3 \times 10^{-5}$ Torr and after the introduction of the argon gas into the chamber the pressure was changed to $5 \times 10^{-2}$ Torr. The presputtering of target was done for $15 \mathrm{~min}$. The cathode discharge current was $160 \mathrm{~mA}$. In the second step, post oxidation annealing of $\mathrm{Zr}$ films was performed in the tube furnace at four different annealing times of 60 , 120, 180 and 240 min, under a constant oxygen flow, at temperature of $450^{\circ} \mathrm{C}$. The structural properties of the prepared films were analyzed by x-ray diffraction $(\mathrm{XRD}$, Philips, pw 1800) with $\mathrm{Cu} \mathrm{K}_{\alpha}$ radiation. The surface morphology of the deposited films was examined using atomic force microscope (AFM, Park Scientific Instrument, Auto probe cp USA). The optical transmittance spectra of $\mathrm{ZrO}_{2}$ films were measured by a spectrophotometer (CARY 500 Scan) in the range of $200-900 \mathrm{~nm}$.

\section{Results and discussion}

The XRD patterns of the $\mathrm{Zr}$ thin films and the $\mathrm{Zr}$ films after thermal oxidation during different time intervals of 60-240 min are shown in Fig. 1a-e. We can observe a peak at $2 \theta=22^{\circ}$ in all XRD patterns, that is due to quartz substrate. In Fig. 1a another peak can be observed which is attributed to diffraction from (100) plane of hexagonal zirconium phase. After thermal oxidation annealing of $\mathrm{Zr}$ films at different annealing times the (111) and (200) crystallographic reflections corresponding to tetragonal zirconium oxide $\left(\mathrm{t}-\mathrm{ZrO}_{2}\right)$ phase appeared in all films (Figs. 1b-e). The presented XRD diagrams agree well with the reports on $\mathrm{ZrO}_{2}$ thin films prepared using sol gel method by Joy et al. [11]. The XRD results show that by increasing the annealing times from 60 to 180 min the intensity of the peaks slightly decreases (Figs. 1b-d) and then at annealing time of $240 \mathrm{~min}$ (Fig. 1e) the intensity of peaks increases again. The average grain size of $\mathrm{t}-\mathrm{ZrO}_{2}$ films calculated from the 
Scherrer's formula [12] using (111) peak was in the range of 14-30 nm, which confirms the presence of nanocrystals in the films. The XRD results of the films prepared in this study show that by post-oxidation annealing of Zr films, the nano-crystalline $\mathrm{ZrO}_{2}$ films with tetragonal structure are produced regardless of the annealing time in the range of $60-240 \mathrm{~min}$.

The surface morphology and the roughness of the films were examined by AFM. The three dimensional AFM images of the deposited films are shown in Figs. 2a-e. The scan area for all images was $2 \times 2 \mu \mathrm{m}^{2}$. The AFM images demonstrate that, before thermal oxidation of $\mathrm{Zr}$ films, the grown grains have a smoother surface (Fig. 2a). By increasing the annealing time from 60 to $240 \mathrm{~min}$ (Figs. 2b-e), the grains combine and make bigger grains and the surface morphology changes from pyramidal type to cluster type surface. The RMS roughness of as deposited films is $1.37 \mathrm{~nm}$. It increases to $1.74 \mathrm{~nm}$ after annealing time of $60 \mathrm{~min}$, probably due to the grains coalescence and formation of zirconium oxide phases that were observed in XRD results. The RMS roughness decreases to 1.54 and $1.31 \mathrm{~nm}$ for annealing time of 120 and $180 \mathrm{~min}$, respectively (Fig. 2c and d). According to XRD results for these annealing times the intensity of zirconium oxide phases slightly decreased. The film annealed for 240 min has an RMS roughness of $2.25 \mathrm{~nm}$ (Fig. 2e). The AFM results confirmed the results obtained by XRD.
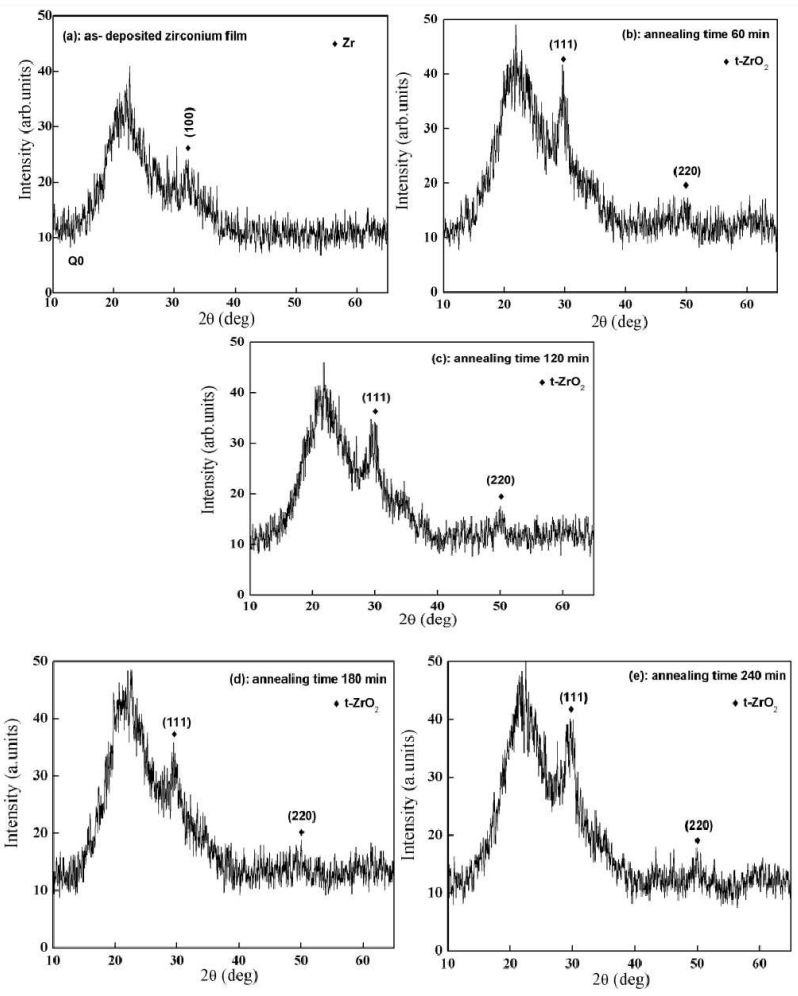

Fig. 1. The XRD patterns of the as deposited $\mathrm{Zr}$ thin films (a) and Zr thin films after thermal oxidation annealing during: (b) $60 \mathrm{~min}$, (c) $120 \mathrm{~min}$, (d) $180 \mathrm{~min}$ and (e) 240 min.
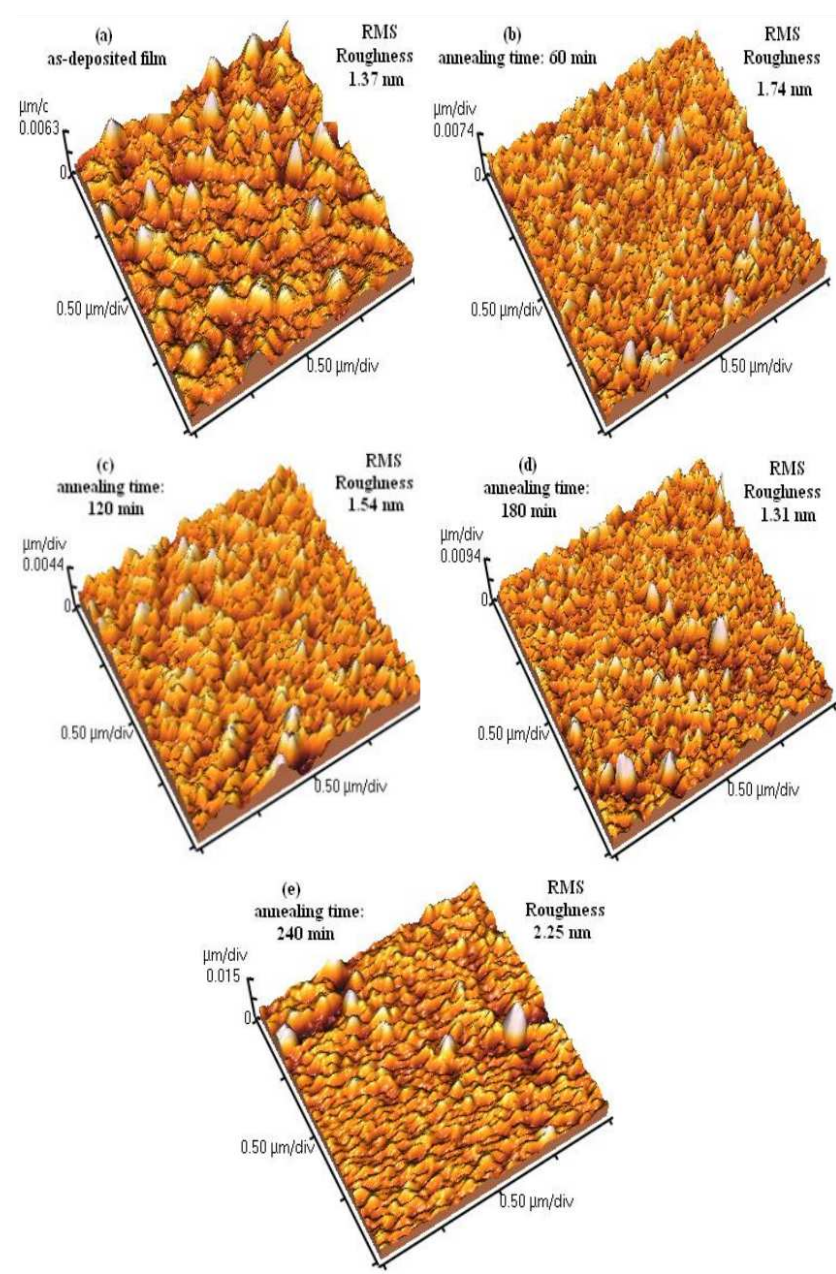

Fig. 2. 3D AFM images of the prepared films: (a) as deposited Zr thin films and Zr films after thermal oxidation annealing during (b) $60 \mathrm{~min}$, (c) $120 \mathrm{~min}$, (d) $180 \mathrm{~min}$, (e) $240 \mathrm{~min}$.

The optical transmittance spectra of $\mathrm{ZrO}_{2}$ films at different annealing times in the wavelength range 200 $900 \mathrm{~nm}$ are shown in Fig. 3a-d. Figure $3 \mathrm{a}-\mathrm{d}$ reveals that the films are transparent in the visible region and the interference fringes observed in transmittance spectra indicate that the prepared films are homogeneous. The transparency and homogeneity of thin films are very important for optical applications. Also, the transmittance increases gradually with the increase of annealing time and the films prepared at annealing time of 120-240 min have the same absorption edge (Fig. 3b-d). The optical constants of the annealed films were calculated using transmittance data using Swanepoel method [13] and the optical band gap energy $E_{g}$ was also obtained using Tauc's relation [14]. The calculated refractive index at wavelength of $500 \mathrm{~nm}$ is in the range 2.10 to 2.25 and the optical band gap energy of prepared zirconium oxide thin films is in the range from 5.55 to $5.58 \mathrm{eV}$. These values are in good agreement with the values reported in $[1,11]$ on $\mathrm{ZrO}_{2}$ thin films. 


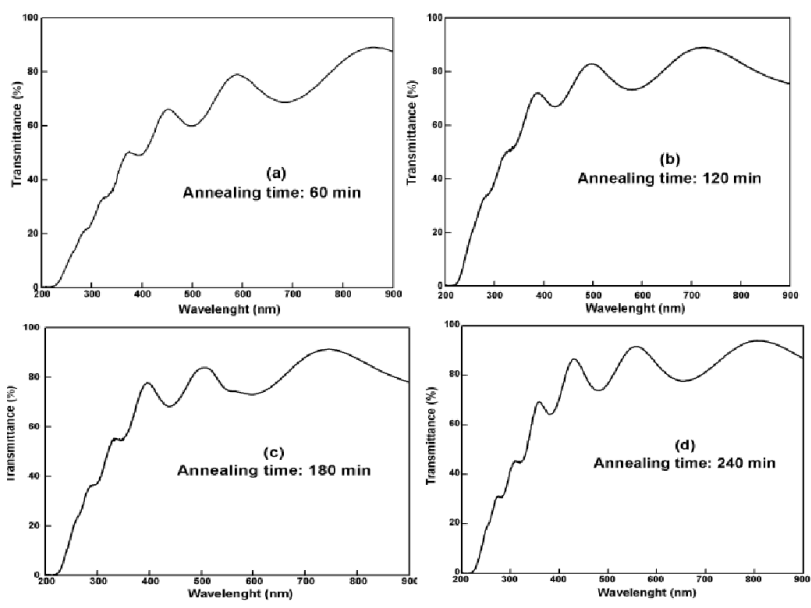

Fig. 3. Transmittance spectra of the $\mathrm{ZrO}_{2}$ films prepared at different oxidation annealing times: (a) $60 \mathrm{~min}$, (b) $120 \mathrm{~min}$, (c) $180 \mathrm{~min}$ and (d) $240 \mathrm{~min}$.

\section{Conclusions}

Transparent, homogeneous nanocrystalline zirconia thin films were prepared by post-oxidation annealing of zirconium thin films deposited on quartz substrates using dc magnetron sputtering method. The dependence of the crystallographic structure, surface morphology and optical properties of the films on the time of annealing was investigated. The XRD results of the films prepared in this study show that by post-oxidation annealing of $\mathrm{Zr}$ films, the nano-crystalline $\mathrm{ZrO}_{2}$ films with tetragonal structure were produced regardless of the annealing time in the range of 60-240 min. Also, the surface morphology of the films strongly depends on annealing time. By increasing the annealing time, the transparency of the zirconia films was increased. The optical band gap energy of the films was in the range of 5.55-5.58 eV. The increase of thermal annealing time has lead to the increase of $\mathrm{ZrO}_{2}$ films refractive index from 2.10 to 2.25 for the wavelength of $500 \mathrm{~nm}$. The optical characterization has shown that the $\mathrm{ZrO}_{2}$ films prepared in this study are highly transparent and homogenous and can be used in optical applications.

\section{Acknowledgments}

This work was supported by Islamic Azad University, Karaj Branch, Karaj, Iran.

\section{References}

[1] F. Rebib, N. Laidani, G. Gottardi, V. Micheli, R. Bartali, Y. Jestin, E. Tomasella, M. Ferrari, L. Thomas, Eur. Phys. J. Appl. Phys. 43, 363 (2008).

[2] L.Q. Zhu, Q. Fang, G. He, M. Liu, L.D. Zhang, Nanotechnology 16, 2865 (2005).

[3] Y. Shen, S. Shao, H. Yu, Z. Fan, H. He, J. Shao, Appl. Surf. Sci. 254, 552 (2007)

[4] Y. Suchorski, R. Wrobel, S. Becker, A. Opalinska, U. Narkiewicz, M. Podsiadly, H. Weiss, Acta Phys. Pol. A 114, S-125 (2008).

[5] N. Li, Y. Abe, M. Kawamura, K.H. Kim, T. Suzuki, Thin Solid Films 520, 5137 (2012).

[6] J. Zhu, T.L. Li, B. Pan, L. Zhou, Z.G. Liu, J. Phys. D: Appl. Phys. 36, 389 (2003).

[7] A. Paskaleva, W. Weinreich, A.J. Bauer, M. Lenberger, L. Frey, Mater. Sci. Semicond. Process. 29, 124 (2015).

[8] K. Galicka-Fau, C. Legros, M. Andrieux, M. Brunet, J. Szade, G. Garry, Appl. Surf. Sci. 255, 8986 (2009).

[9] S. Wang, G. Xia, X. Fu, H. He, J. Shao, Z. Fan, Thin Solid Films 515, 3352 (2007).

[10] D. Panda, T-Y. Tseng, Thin Solid Films 531, 1 (2013).

[11] K. Joy, I. John, K. Joy, I.J. Berlin, P.B. Nair, J.S. Lakshmi, G.P. Daniel, P.V. Thomas, J. Phys. Chem. Solids 72, 673 (2011).

[12] A. Hojabri, F. Hajakbari, A. Emami Meibody, J. Theor. Appl. Phys 9, 67 (2015).

[13] F. Hajakbari, M.M. Larijani, M. Ghoranneviss, M. Aslaninejad, A. Hojabri, Jpn. J. Appl. Phys. 49, 095802 (2010).

[14] J. Tauc, A. Menth, J. Non-Cryst. Solids 8, 569 (1972). 